\title{
MEDIDAS LINEARES NA ESTIMATIVA DA ÁREA FOLIAR DO CAPIM- ARUANA
}

\author{
GALZERANO, Leandro ${ }^{1 *}$ \\ MALHEIROS, Euclides Braga ${ }^{1}$ \\ MORGADO, Eliane da Silva ${ }^{1}$ \\ SILVA, Wilton Ladeira ${ }^{1}$ \\ COSTA, João Paulo Ramos ${ }^{1}$ \\ CAPUTTI, Gregory de Paula ${ }^{1}$ \\ RUGGIERI, Ana Claudia ${ }^{1}$
}

RESUMO: O experimento foi conduzido na Faculdade de Ciências Agrárias e Veterinárias/UNESP, Campus de Jaboticabal. Para realização deste estudo foram coletadas 15 folhas ao acaso do capim Panicum maximum cv. Aruana em fevereiro de 2010 quando o capim encontrava-se com 27 dias de rebrotação (terceiro corte), com objetivo de se estimar por meio de dimensões lineares, a área foliar correspondente. Avaliou-se correlações entre a área foliar real (AFR) e o produto do comprimento e a largura máxima das folhas $(C \mathrm{x} \mathrm{L})$, o comprimento máximo das folhas $(\mathrm{C})$ e a largura máxima das folhas (L). Utilizou-se neste estudo folhas de diferentes tamanhos e posições no dossel. Os resultados permitem concluir que a estimativa da área foliar do capim-aruana pode ser realizada utilizando-se a dimensão do comprimento foliar a qual gerou a equação $\mathrm{AF}=0,96$ x (C) - 4,8 com coeficiente de determinação de 0,90 .

Palavras-chave: Dimensão foliar. Ecofisiologia. Panicum maximum.

SUMMARY: The experiment was carried out at Faculdade de Ciências Agrárias e Veterinárias/UNESP, Jaboticabal. For this study 15 leaves were collected at random from the Panicum maximum cv. Aruana grass in February 2010 when the grass was with 27 days of regrowth (third cut), in order to estimate by linear dimensions, the corresponding leaf area. It was evaluated the correlations between leaf area (LA) and the product of length and width of leaves ( $\mathrm{Lx} \mathrm{W})$, length of leaves $(\mathrm{L})$ and the maximum width of leaves (W). It was used in this study leaves of different sizes and positions in the canopy. The results indicate that estimates of leaf area of aruana grass can be performed using the length of the leaf which generated the equation $L A=0.96 \times(L)-$ 4.8 with a coefficient of determination of 0,90 .

Keywords: Ecophysiology. Leaf dimensions. Panicum maximum.

\section{INTRODUÇÃO}

Pesquisas sobre as respostas ecofisiológicas são de grande importância para o manejo de pastagens de gramíneas. A fotossíntese á e força motriz do crescimento vegetal e produção animal e é dependente da área e eficiência do tecido verde da planta. Estudos sobre estratégias de pastejo com plantas forrageiras têm se concentrado na interceptação de luz bem como no principal aparato captador de luz, a área foliar, quanto a sua forma, distribuição e mobilidade em relação a radiação recebida ('T MANNETJE, 2002). Dessa forma, conhecimento do desenvolvimento foliar é importante para a compreensão de respostas das plantas aos diferentes manejos adotados. De acordo com Lopes et al. (2004), a área foliar pode ser medida ou estimada por métodos destrutivos e não destrutivos. Entre as inúmeras possibilidades para se determinar a área foliar o método não destrutivo que utiliza correlações entre área foliar com

\footnotetext{
${ }^{1}$ Faculdade de Ciências Agrárias e Veterinárias, Universidade Estadual Paulista - Unesp, 14884-900, JaboticabalSP, Brasil. *E-mail: galzeranorural@yahoo.com.br
} 
comprimento e largura do limbo foliar, é o mais utilizado e tem gerado equações com excelente precisão de estimativa (PINTO et al., 2007). O objetivo com este trabalho é definir com base no comprimento e largura foliar, equações simples para estimar a área foliar do capim Panicum maximum cv. Aruana.

\section{MATERIAL E MÉTODOS}

O experimento foi conduzido na Faculdade de Ciências Agrárias e Veterinárias/ Unesp, Campus de Jaboticabal, SP, localizada a $21^{\circ} 15$ '22' de latitude sul, longitude de $48^{\circ} 18^{\prime} 58^{\prime}$ ' $\mathrm{W}$, a uma altitude de $595 \mathrm{~m}$. O solo da área experimental foi classificado como Latossolo Vermelho Distrófico, textura argilosa, horizonte A moderado, caulinítico hipoférrico com relevo suave ondulado (EMBRAPA, 2006). Uma análise da camada arável do solo realizada em novembro de 2009, indicou as seguintes propriedades

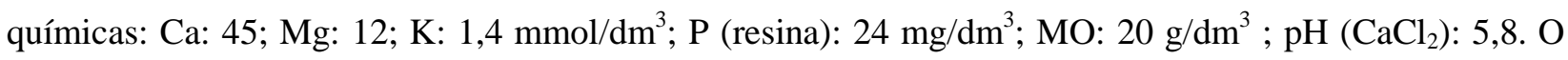
clima de Jaboticabal, de acordo com a classificação de Köppen é classificado como tropical do tipo Aw, mesotérmico com verão úmido e inverno seco. A precipitação pluvial durante o período experimental foi de 163,$3 ; 383,7 ; 240,7$; e $150,7 \mathrm{~mm}$ para os meses de novembro e dezembro de 2009 e janeiro e fevereiro de 2010, respectivamente. Na realização deste estudo foi utilizada uma área experimental de $35,0 \mathrm{~m}^{2}$. O capim foi mantido sob cortes a $5 \mathrm{~cm}$ do solo a cada 28 dias e a adubação consistiu na aplicação de $100 \mathrm{~kg}$ de N/ha/ano na forma de Uréia, $30 \mathrm{~kg}$ de $\mathrm{P}_{2} \mathrm{O}_{5} / \mathrm{ha} / \mathrm{ano}$ na forma de Superfosfato Simples e 100 de $\mathrm{K}_{2} \mathrm{O} / \mathrm{ha} / \mathrm{ano}$ na forma de Cloreto de Potássio aplicados em única dose em dezembro de 2009 após realização do primeiro corte, a fim de garantir níveis satisfatórios de fertilidade para desenvolvimento das plantas. Para realização deste estudo foram coletadas 15 folhas ao acaso do capim Panicum maximum cv. Aruana em fevereiro de 2010 quando o capim encontrava-se com 27 dias de rebrotação (terceiro corte). A área foliar (AF) foi calculada como produto das duas dimensões, comprimento (C) e largura (L), e um fator "f" como sendo: $\mathrm{AF}=\mathrm{f} \times(\mathrm{C} \times \mathrm{L})$ onde o fator "f" foi determinado pela relação entre a área de uma amostra de folhas e o produto de suas dimensões conforme descrito por Monteiro et al. (2005). As folhas utilizadas para análise foram coletadas e levadas para bancada à sombra a fim de se evitar a desidratação e dificuldades no manuseio onde foram então medidas e anotadas as suas dimensões. Posteriormente, as folhas foram escaneadas com auxilio do integrador de área foliar de mesa ("Portable Area Meter" Licor Mod. L1 - 3000), para determinação da área foliar real. Os resultados foram submetidos à análise de regressão.

\section{RESULTADOS E DISCUSSÃO}

Os resultados de regressão efetuados neste trabalho, relacionando a área foliar real (AF) e as medidas lineares de comprimento $(\mathrm{C})$, largura $(\mathrm{L})$ e o produto do comprimento pela largura da folha $(\mathrm{C} \mathrm{x}$ L), estão nas Figuras 1, 2 e 3.

As dimensões das folhas utilizadas para o estudo variaram amplamente de 12,0 a $34,5 \mathrm{~cm}$ de comprimento e de 0,8 a 1,3 cm de largura, confirmando desta forma a coleta de folhas de diferentes tamanhos para realização do estudo.

Observa-se na Figura 1, que a relação entre área foliar e comprimento $(\mathrm{C}) \mathrm{x}$ largura $(\mathrm{L})$, possibilita a estimação da área foliar através da equação $\mathrm{AF}=0.62 \times(\mathrm{C} \times \mathrm{L})+1,4$ com coeficiente de determinação 0,94 . 
Figura 1. Relação entre a área foliar e a área resultante do comprimento x largura da folha de capim-aruana.

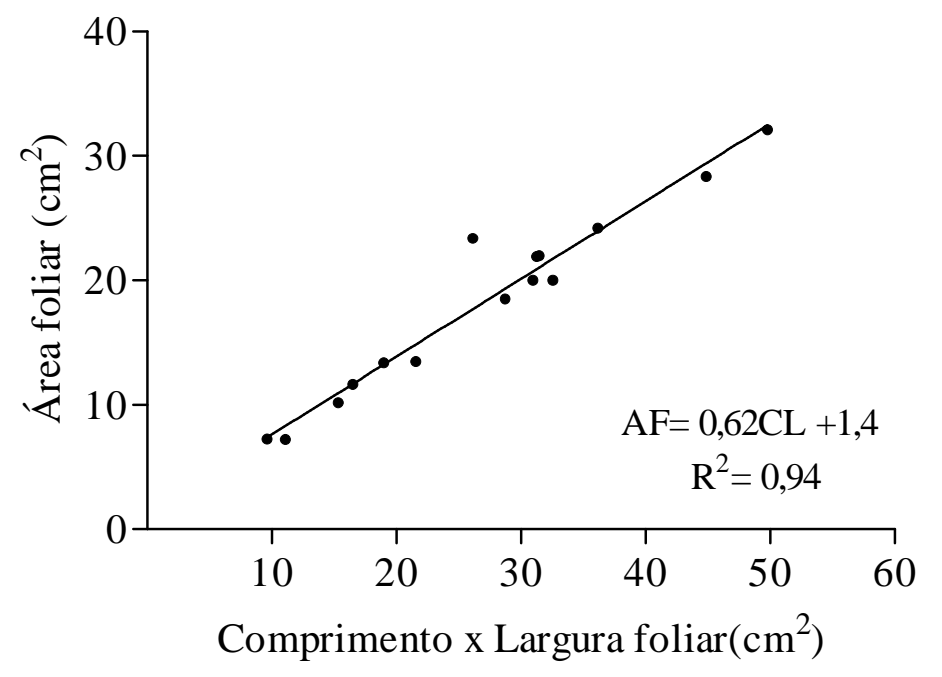

Na Figura 2, pode-se observar que os dados referentes à área foliar relacionada com o comprimento máximo das folhas permitem concluir que a equação obtida $\mathrm{AF}=0,96 \times(\mathrm{C})-4,8$ pode ser utilizada para estimar a área foliar, com coeficiente de correlação de 0,90 .

Figura 2. Relação entre o comprimento da folha e a área foliar de capim-aruana.

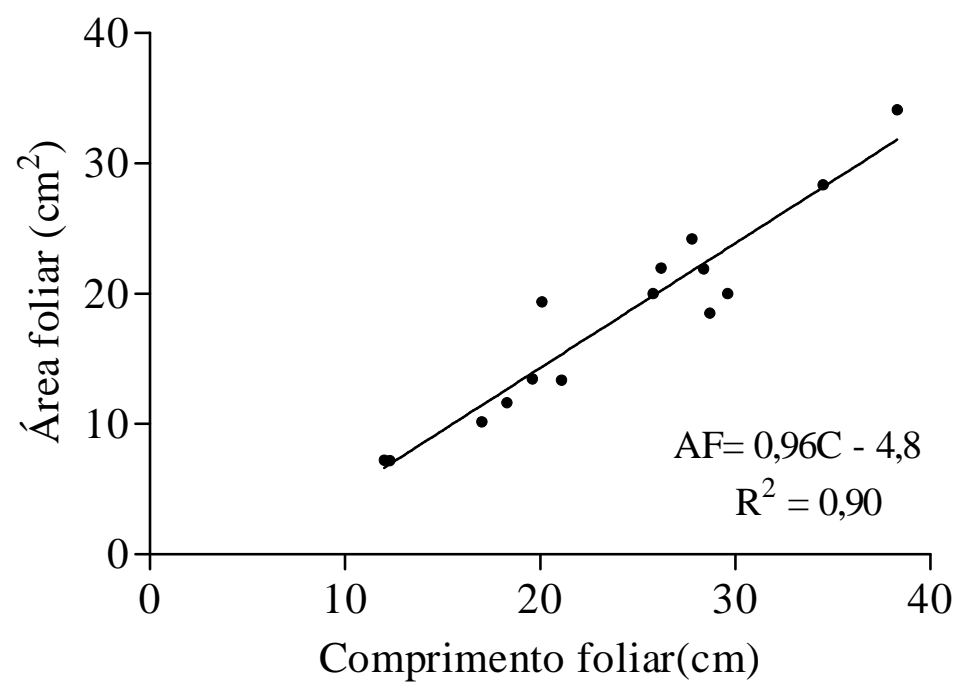

Pode-se observar na Figura 3, que os dados referentes à área foliar relacionada com a largura, se ajustam a equação, porém com coeficiente de determinação de 0,81 e equação obtida $A F=37,7$ x (L) 23,86 . 
Figura 3. Relação entre a largura da folha e a área foliar de capim-aruana.

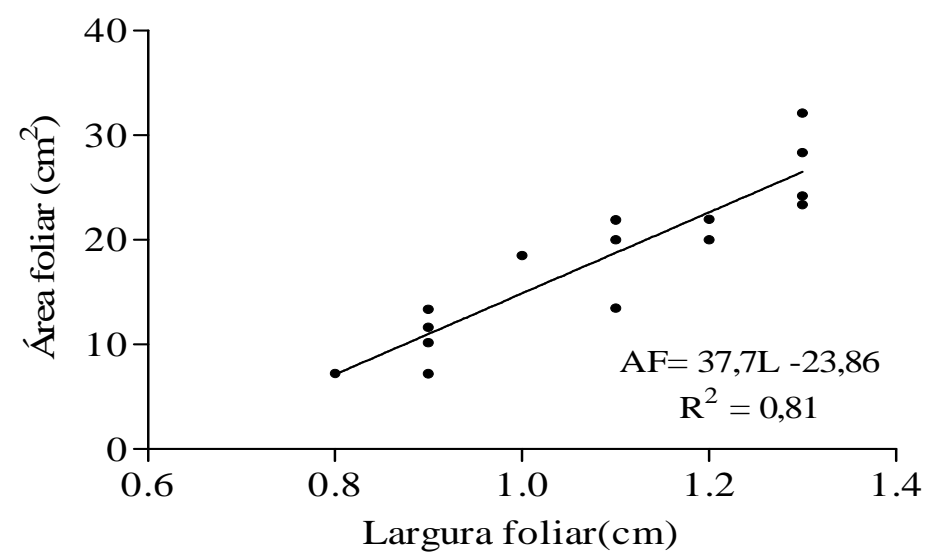

Os valores encontrados neste trabalho possibilitam a estimação da área foliar do capim Aruana com o uso da dimensão do comprimento e largura das folhas uma vez que a sua equação apresentou maior coeficiente de determinação comparado à largura.

Neste trabalho, o resultado obtido com a estimativa da área foliar com a largura foliar foi o que apresentou equação com menor coeficiente de determinação o que pode ser explicado devido ao desenvolvimento menos acelerado da dimensão da largura em relação à área foliar real. Segundo Queiroga et al. (2003), a precisão de equações para estimativa de área foliar, dentre as várias possibilidades ou de combinações entre parâmetros dimensionais e modelos de regressão, relaciona-se não só com o formato da folha, mas também com a sua variação durante o crescimento da planta.

\section{CONCLUSÃO}

A área foliar do capim-aruana pode ser estimada pela dimensão de comprimento $\mathrm{x}$ largura da folha com a equação: $\mathrm{AF}=0,62(\mathrm{CL})+1,4$.

\section{REFERÊNCIAS}

EMBRAPA- EMPRESA BRASILEIRA DE PESQUISA AGROPECUÁRIA. Sistema Brasileiro de Classificação de Solos. Brasília: EMBRAPA, 2006. 306p.

LOPES, C.M.et al. Modelos empíricos para estimativa da área foliar da videira na Casta Jaen.

Ciência Técnica Vitivinicultura. v.19, n.2, p. 61-75, 2004.

MONTEIRO, J.E.B.A.et al. Estimação da área foliar do algodoeiro por meio de dimensões e massa das folhas. Bragantia, Campinas, v.64, n.1, p.15-24, 2005.

PINTO, M.S.C.et al. Modelo para estimativa da área foliar da maniçoba. Revista Ciência Agronômica, v.38, n.4, p.391-395, 2007.

QUEIROGA, J.L.et al. Estimativa da área foliar do feijão-vagem (Phaseolus vulgaris L.) por meio da largura máxima do folíolo central. Horticultura Brasileira, Brasília, v.21, n.1, p. 64-68, 2003.

'T MANNETJE, L. Advances in grassland science. Netherlands Journal of Agricultural Science. v.50, n.2, p.195-221, 2002. 